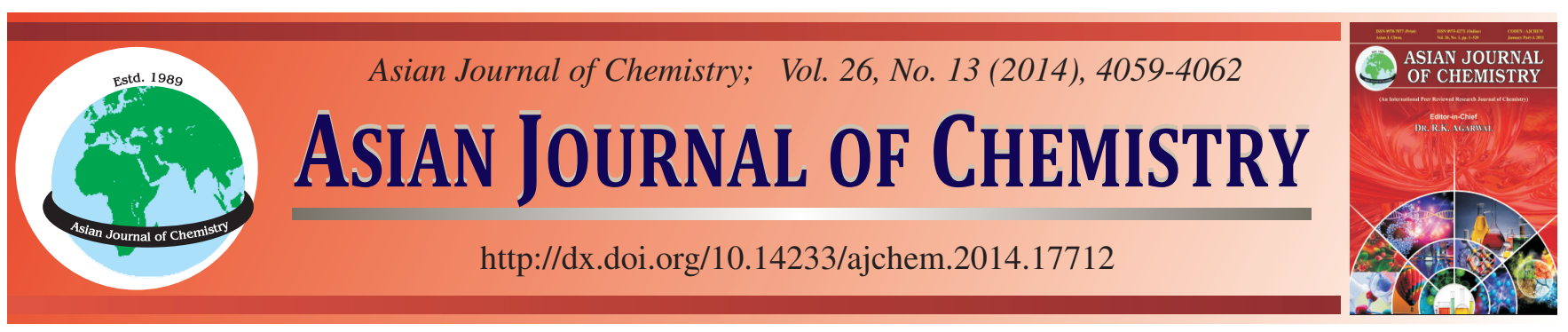

\title{
Stability of Electrode Materials During Electrolysis in LiCl-KCl Melt $\dagger$
}

Dae-Hyeon Kim ${ }^{1,2}$, SAng-Eun BaE ${ }^{1, *}$, TAe-Hong ParK ${ }^{1}$, Kyuseok Song ${ }^{1, *}$ and Jong-Ho Chö ${ }^{2}$

${ }^{1}$ Nuclear Chemistry Research Division, Korea Atomic Energy Research Institute, 989-111 Daedeok-daero, Yuseong-gu, Daejeon 305-353, Republic of Korea

${ }^{2}$ Department of Chemistry, Korea University, Seoul 339-700, Republic of Korea

*Corresponding author: Fax: +82 42 8688148; E-mail: sebae@kaeri.re.kr; sks@kaeri.re.kr

Tungsten, molybdenum and carbon were tested for the electrodes in $\mathrm{LiCl}-\mathrm{KCl}$ melt at $450^{\circ} \mathrm{C}$ using electrochemical and scanning electron microscopic techniques. Open circuit potentials for the $\mathrm{W}$ and Mo electrodes were stabilized near -0.23 and $-0.41 \mathrm{~V}$, respectively while that of the carbon electrode is slowly shifted from 0 to $-0.33 \mathrm{~V}$. Cyclic voltammetry and SEM results show that the metal electrodes can be corroded in an anodic potential range. The carbon electrode was stable at a potential more positive than $-1.0 \mathrm{~V}$ but became coarse at a more negative potential. Using these results, the electrode materials were evaluated for usage in $\mathrm{LiCl}-\mathrm{KCl}$ melt and relatively stable electrode materials for the pyrochemical process were suggested.

Keywords: Pyrochemical process, Electrode materials, Molten salt, LiCl-KCl.

\section{INTRODUCTION}

Chloride based molten salts have been extensively used as an electrolyte in the pyrochemical process ${ }^{1-3}$. The pyrochemical process requires high temperatures, in general over $400{ }^{\circ} \mathrm{C}$, to fuse the salt and a Cl-based medium under such conditions is very harsh for most materials $\mathrm{s}^{4,5}$. For example, the electrodeposition of uranium onto a carbon electrode leads to a problem of the intercalation of Li into a carbon surface. It is well-known that $\mathrm{Li}$ intercalates into the carbon electrode at around $-1.1 \mathrm{~V} v s . \mathrm{Ag} \mid \mathrm{Ag}^{+6}$. In other words, the potential window of the carbon must be negatively limited to $-1.1 \mathrm{~V}$. Additionally the carbon becomes gradually roughened and degraded by the $\mathrm{Li}$ intercalation during electrochemical measurement in the molten salt ${ }^{7}$.

Metal electrodes such as W and Mo have also been used as a working electrode in chloride based molten salt ${ }^{8}$. After a long- running experiment, however, the molten salt electrolytes often have a tendency to become black, which indicates that a metal electrode is not perfectly durable for the electrochemical measurement in Cl-based molten salt ${ }^{9}$. Therefore, it is challenging to find the electrode materials that are durable and stable in the environment of the pyrochemical process.

In this work, we employed electrochemical and scanning electron microscopy (SEM) techniques to investigate the stability of the electrode materials in LiCl-KCl melt. Cyclic voltammetry (CV) and open circuit potential (OCP) measurements were performed to investigate the reactivity of electrode materials in Cl-based molten salt whereas SEM studies revealed the morphology changes of the electrode surface, which accompanied the electrochemical reactions in $\mathrm{LiCl}-\mathrm{KCl}$ melt.

\section{EXPERIMENTAL}

Lithium chloride-potassium chloride eutectic salts (anhydrous beads) were obtained from Sigma-Aldrich Co. Ltd. (purity $\geq 99.999 \%$ ). Sliver chloride and neodymium chloride were purchased from Alfa Aesar (purity $\geq 99.998 \%$ ).

An electrochemical reaction vessel was made out of a quartz tube (length $350 \mathrm{~mm}$; outer diameter $20 \mathrm{~mm}$; wall thickness $2 \mathrm{~mm}$ ). Carbon or $\mathrm{W}$ electrodes were used as a counter electrode, as described elsewhere ${ }^{9}$. The electrodes were encased in quartz tubes to prevent electrical contact with other electrodes. The $\mathrm{Ag} \mid \mathrm{Ag}^{+}$reference electrode tube contains $\mathrm{AgCl}$ (1.0 wt \%) in the $\mathrm{LiCl}-\mathrm{KCl}$ eutectic melts. Silver wire was then inserted into the tube until it was immersed in the molten salts. Lastly, the top of the tube was sealed with Teflon tape to prevent evaporation of the molten salts at high temperature.

The temperature of the molten salt was measured within an accuracy of $1^{\circ} \mathrm{C}$ using a calibrated K-type Chromel-Alumel 
thermocouple wire. Cyclic voltammograms were obtained using Autolab PGSTAT 100 interfaced with a PC at a scan rate of $200 \mathrm{mV} / \mathrm{s}$. All experiments were conducted inside a glove box under argon $(99.999 \%$ ), in which the oxygen content and moisture levels were maintained at less than $1 \mathrm{ppm}$.

\section{RESULTS AND DISCUSSION}

Cyclic voltammetry: Fig. 1 shows cyclic voltammograms (CV) of W, Mo and carbon working electrodes in $\mathrm{LiCl}-\mathrm{KCl}$ melt. In curves (a) and (b) obtained from W and Mo wires, respectively, large cathodic and anodic peaks near $-2.4 \mathrm{~V} v s$. $\mathrm{Ag} \mid \mathrm{Ag}^{+}$were observed, which are associated with the $\mathrm{Li}$ deposition and dissolution reactions. Between $-2.4 \mathrm{~V}$ and +0.2 $\mathrm{V}$, a featureless double layer region was detected. At $+1.1 \mathrm{~V}$, a chlorine gas evolution reaction occurred. These are consistent with the results in the literature ${ }^{9}$. In curve (b), the Mo electrode led to an oxidation current at around $+0.4 \mathrm{~V}$ and a corresponding cathodic current at $-0.4 \mathrm{~V}$. These REDOX peaks can be assigned to the oxidation and reduction reactions between Mo and $\mathrm{K}_{3} \mathrm{MoCl}_{6}{ }^{8}$.

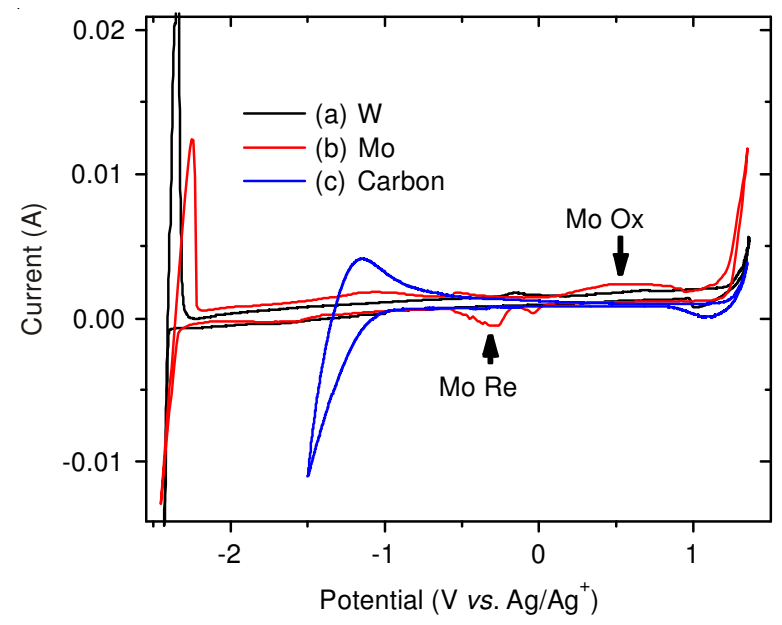

Fig. 1. Cylic voltammograms obtained from W (a), Mo (b) and carbon (c) electrode in $\mathrm{LiCl}-\mathrm{KCl}$ melt

Curve (c) shows the CV obtained from a carbon electrode. Unlike the metal electrodes, a large reduction current began to increase at $-1.0 \mathrm{~V}$. This cathodic current resulted from a $\mathrm{Li}$ intercalation reaction into the carbon electrode. There was a smaller corresponding anodic current on the positive potential sweep, indicating that most of the Li ions intercalated into the carbon electrode were not deserted during the anodic sweep. The chlorine gas evolution current at the carbon electrode was also observed at the same potential for the metal electrodes.

Open circuit potential: Fig. 2 shows changes in open circuit potential (OCP) as a function of time when the W, Mo and carbon electrodes were contacted with high temperature molten salt. All open circuit potential values started from a positive value as soon as the electrodes contacted the LiCl$\mathrm{KCl}$ melt and decreased abruptly toward $-0.2 \mathrm{~V}$. If the initial part (Fig. 1) for the metal electrodes is closely looked into, the open circuit potential values, strictly speaking, first move toward a positive direction. This means that the initial electro-

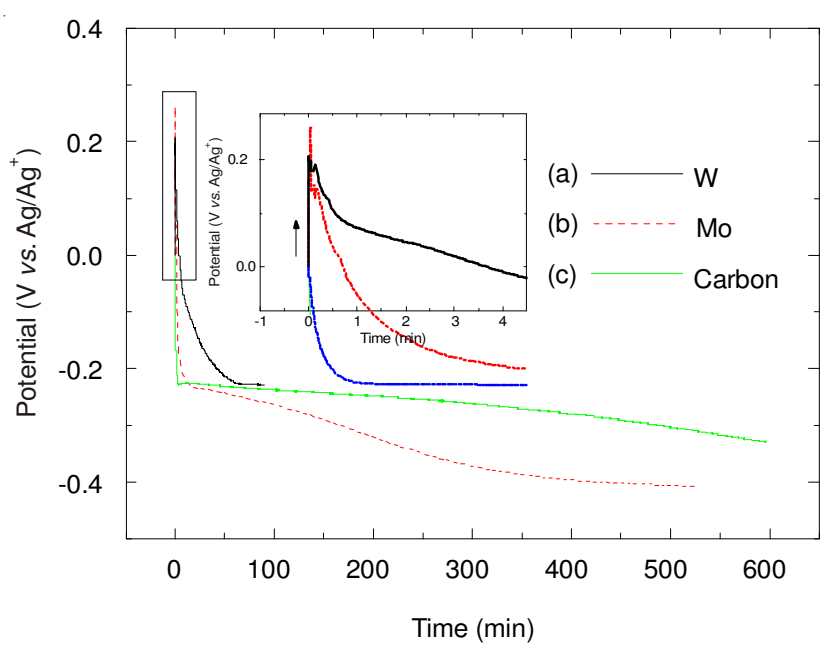

Fig. 2. Open circuit potential measurements of W (a), Mo (b) and carbon (c) electrodes in $\mathrm{LiCl}-\mathrm{KCl}$ melt. The inset is an enlargement of the square

chemical reaction is dominated by the reduction reaction of the metal surface. Here, the positive shift in open circuit potential value can be attributed to the reduction of oxide species on the metal surface formed under ambient conditions. After the metal oxide reduction, the open circuit potential values decreased to $-0.2 \mathrm{~V}$ which reflects that the oxidation reaction became dominant. In the case of $\mathrm{W}$, the open circuit potential value was stabilized at $-0.23 \mathrm{~V}$ in $1 \mathrm{~h}$ but for the Mo electrode it took $10 \mathrm{~h}$ to be stabilized at $-0.41 \mathrm{~V}$. In case of the carbon electrodes (glassy carbon), it is difficult to obtain the plateau value of the open circuit potential in the measurement up to $600 \mathrm{~min}$ in this work.

Electrodeposition of metal: Fig. 3 shows CVs obtained from the $\mathrm{W}$ electrodes in $\mathrm{LiCl}-\mathrm{KCl}$ melt containing $\mathrm{UCl}_{3}$ and $\mathrm{NdCl}_{3}$. The electrodeposition reaction of $\mathrm{U}$ occurred at -1.43 $\mathrm{V}$ and peaked at $-1.48 \mathrm{~V}$. In the returning sweep, the anodic dissolution current exhibited a peak at $-1.33 \mathrm{~V}$. Around $-0.2 \mathrm{~V}$, there were anodic and cathodic currents attributable to REDOX reactions of $\mathrm{U}^{3+/ 4+}$. For the $\mathrm{LiCl}-\mathrm{KCl}$ melt containing $\mathrm{NdCl}_{3}$, current peaks of $\mathrm{Nd}$ electrodeposition and dissolution reactions were observed at -2.14 and $-1.99 \mathrm{~V}$, respectively. This result agrees with the literature $\mathrm{e}^{10,11}$.

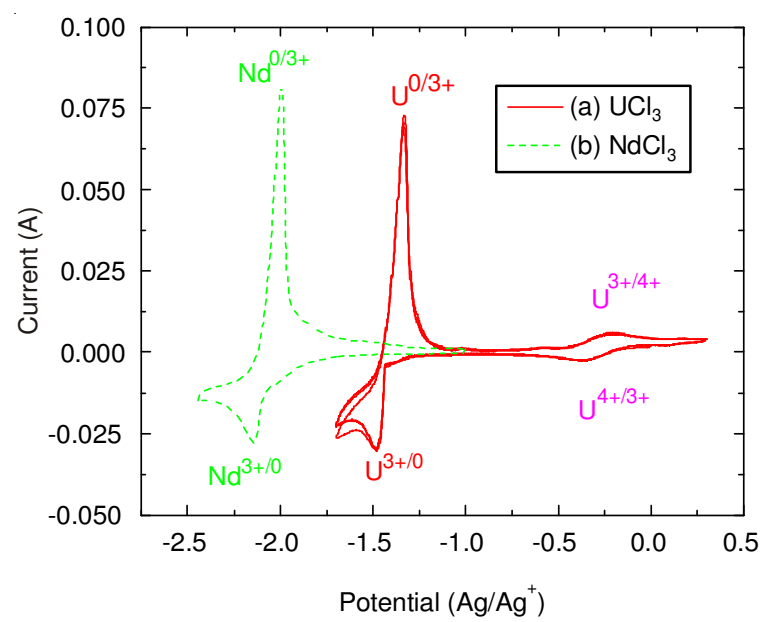

Fig. 3. Cyclic voltammograms obtained from $\mathrm{W}$ electrodes in $\mathrm{LiCl}-\mathrm{KCl}$ melt containing $\mathrm{UCl}_{3}$ (a) and $\mathrm{NdCl}_{3}$ (b). The scan rate was $100 \mathrm{mV} / \mathrm{s}$ 
Scanning electron microscopy: To investigate the surface morphology change of the electrode by electrochemical reactions in LiCl-KCl melt, scanning electron microscopy (SEM) measurements were performed. Fig. 4 shows the SEM images obtained from the electrode surfaces before and after electrochemical reactions in $\mathrm{LiCl}-\mathrm{KCl}$ melt at $450^{\circ} \mathrm{C}$. Before the experiments, the surfaces of W (a), Mo (b) and carbon (c) exhibited the typical properties of metal and graphite surfaces. After 100 cycles of $\mathrm{Li}$ deposition and dissolution reactions between -1 and $-2.5 \mathrm{~V}$, the metal surfaces of the $\mathrm{W}$ and Mo electrodes ( $a$ ' and b', respectively) were nearly intact while the carbon surface (c') became rough and tended to peel off. On the other hand 100 times of chlorine evolution reactions by applying the potential between $0 \mathrm{~V}$ and $+1.5 \mathrm{~V}$ rendered the metal surfaces extensively coarse. The W surface (a") seemed to be dug out, which produced many large holes. In image (b") of the Mo electrode, many white spots can be observed on the surface. These particles may result from the precipitation of oxidized Mo species. In case of the carbon electrode (c"), small white particles can be seen on the whole surface.

Fig. 5 shows SEM images taken from the $\mathrm{W}$ and carbon electrode surfaces after 100 times of electrodeposition and dissolution reactions of $\mathrm{Nd}$ and $\mathrm{U}$. After the electrochemical reactions of $\mathrm{Nd}$, the morphology of the $\mathrm{W}$ surface (Fig. 5a) seemed to be
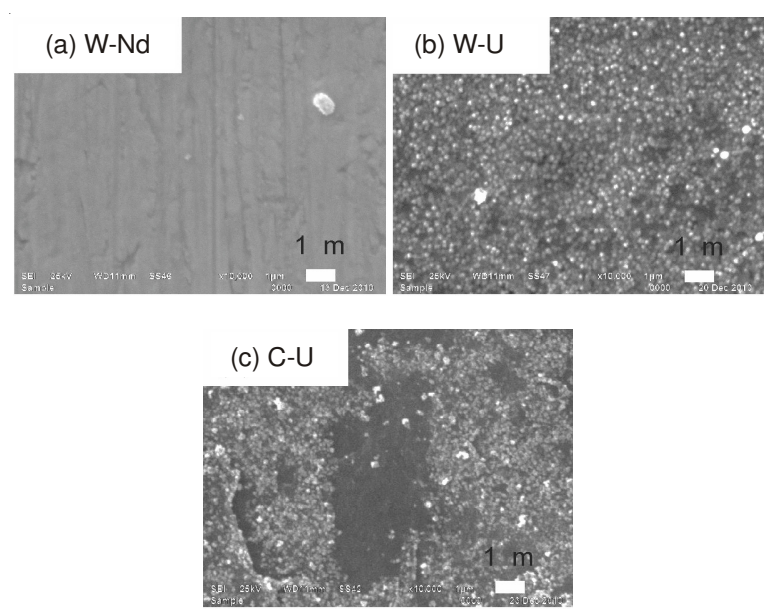

Fig. 5. SEM images taken from $\mathrm{W}(\mathrm{a}, \mathrm{b})$ and carbon (c) electrode surfaces after 100 times of electrodeposition and dissolution reactions of $\mathrm{Nd}$ (a) and $\mathrm{U}(\mathrm{b}, \mathrm{c})$. The $\mathrm{CV}$ ranges for the reactions were restricted from -1 to $-1.6 \mathrm{~V}$ and to $-2.2 \mathrm{~V}$ for $\mathrm{U}$ and $\mathrm{Nd}$, respectively

same as the initial one shown in Fig. 4a. This means that the W electrode was stable during the electrodeposition and dissolution reactions. However, the electrodeposition and dissolution reactions of $\mathrm{U}$ (b) on the $\mathrm{W}$ electrode left a large number of particles on the surface. The EDX results (not shown) exhibits that the
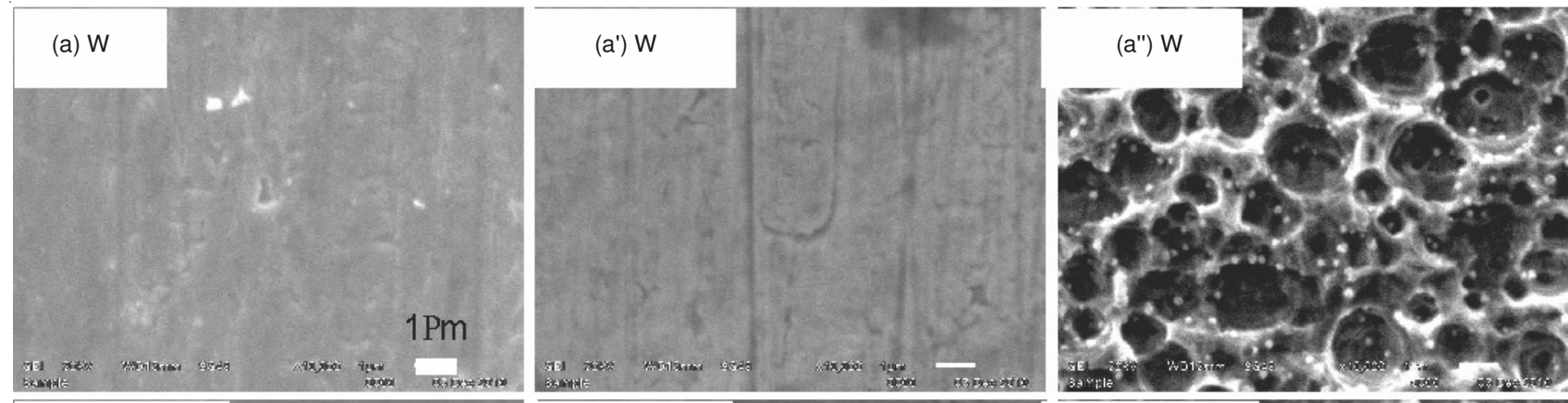

(b) Mo
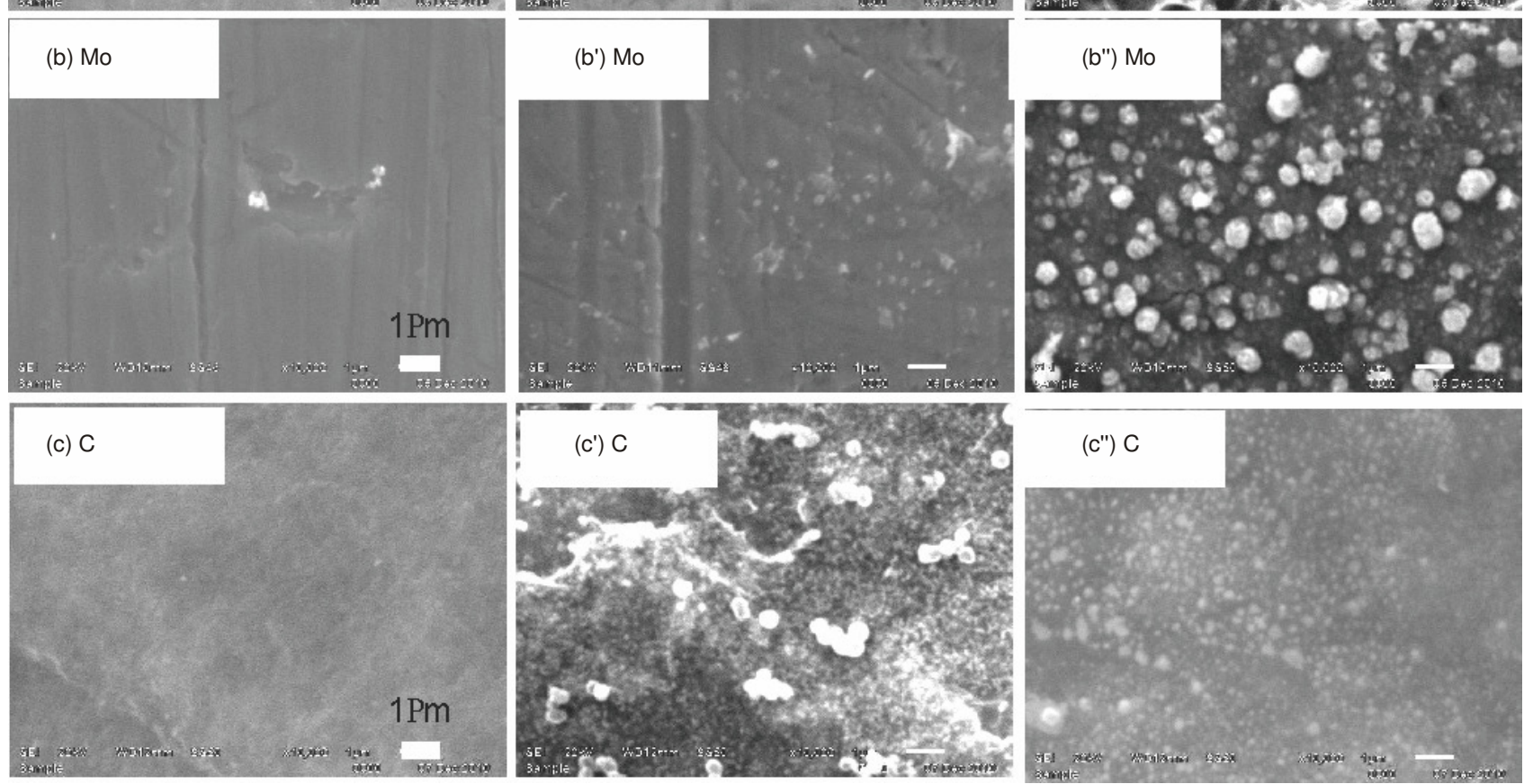

Fig. 4. SEM images obtained from (a) W, (b) Mo and (c) carbon electrode surfaces before and after electrochemical reactions. (a), (b) and (c) are the surface images before the electrochemical reactions. ( $x^{\prime}$ ) and ( $\left.x^{\prime \prime}\right)$ were taken after 100 times of CV cycles between -1 and $-2.5 \mathrm{~V}$ and between 0 and $+1.5 \mathrm{~V}$, respectively. For (b") image, the $\mathrm{CV}$ range was restricted between 0 and $+0.5 \mathrm{~V}$ 
particles were composed of $5.3 \mathrm{wt}$ \% $\mathrm{U}$ and $94.7 \mathrm{wt}$ \% W. This result implies that the alloy between $\mathrm{U}$ and $\mathrm{W}$ was formed and not dissolved even at a potential much more positive than that of the $\mathrm{U}$ dissolution. For the carbon electrode, the morphology became extensively rough and many small particles were spread on the surface after the $U$ electrodeposition and dissolution reactions. The surface also seemed to be peeled off in a film form.

The results presented herein provide considerable insight regarding the stability of electrode materials in $\mathrm{LiCl}-\mathrm{KCl}$ melt. In particular, the results reveal that the selection of electrode materials for an electrochemical system of $\mathrm{LiCl}-\mathrm{KCl}$ melt. The $\mathrm{CV}$ result showed that the $\mathrm{W}$ and Mo electrodes were relatively stable at the cathodic potential range up to the lithium deposition reaction while the carbon electrode possesses a limited cathodic potential range up to $-1.0 \mathrm{~V}$. For the anodic potential range, the carbon electrode did not show any reaction except for the chlorine evolution reaction. The Mo electrode was oxidized at $+0.4 \mathrm{~V}$.

According to the open circuit potential results, $\mathrm{W}$ electrode showed the highest open circuit potential value among the three materials. The open circuit potential results can provide impor-tant information such as the local equilibrium established by the involved REDOX species near the electrode surface ${ }^{12}$. In the $\mathrm{LiCl}-\mathrm{KCl}$ melt, $\mathrm{Li}^{+}$and $\mathrm{Cl}^{-}$are the most abundant elements. Thus, the Li deposition reaction is a dominant reaction, while the oxidation reaction results from the chlorine evolution reaction. On the metal electrode surface, the oxidation and reduction reaction of the metal may also take place. In case of a carbon electrode, the $\mathrm{Li}$ intercalation reaction predominantly occurs as a cathodic reaction ${ }^{9}$. Because the open circuit poten-tial value can be deduced as being identified as a REDOX mixed potential of cathodic and anodic reactions, the more negative oxidation potential of the Mo electrode than those of the $\mathrm{W}$ and carbon electrodes may push the open circuit potential of the Mo electrode toward a negative direction. This means that the Mo electrode can be corroded more easily than the other materials. For the carbon electrode, because the Li inter-calation reaction takes place at a potential much more positive than at those for metal electrodes, the open circuit potential value for the carbon electrode can be more positive. However, the open circuit potential value for the carbon electrode was not such higher than the others. This can be explained by the $\mathrm{Li}$ accumulation in the carbon electrode. According to the $\mathrm{CV}$ result of the carbon electrode, Li intercalated in the carbon electrode did not fully come out and thus the Li was accumu-lated in the carbon electrode and the insertion and desertion of $\mathrm{Li}^{+}$ions in the carbon electrode then likely reached an equilibrium state. The carbon electrode, which bears Li inside, can act as an easily oxidizable Li electrode. As a result, the contribution of the $\mathrm{Li}$ intercalation reaction for the open circuit potential value can be compensated with the oxidation reaction of $\mathrm{Li}$.
Therefore, the open circuit potential value for the carbon electrode can be similar to those of the metal electrodes. According to the SEM results, the metal electrodes were easily corroded at the potential range of chlorine gas evolution while the carbon electrode was not stable in the potential range of the electrodeposition of $\mathrm{U}$ and $\mathrm{Nd}$. In conclusion, the metal electrodes can be useful as a cathodic electrode. A carbon electrode can be a good alternative for an anodic electrode in the pyrochemical process.

\section{Conclusion}

For use as an electrode in the pyrochemical process, W, Mo and carbon were tested using electrochemical and scanning electron microscopic (SEM) techniques. The open circuit potentials (OCP) for the $\mathrm{W}$ and Mo electrodes were stabilized near -0.23 and $-0.41 \mathrm{~V}$, respectively while the open circuit potential for the carbon electrode was slowly shifted from $0 \mathrm{~V}$ to $-0.33 \mathrm{~V}$. The cyclic voltammetry and SEM results exhibited that the metal electrodes can be corroded in an anodic potential range. The carbon electrode was stable at a potential more positive than $-1.0 \mathrm{~V}$ but roughened at a more negative potential. As a result, the metal electrodes are durable in the $\mathrm{LiCl}-\mathrm{KCl}$ melt as a cathodic electrode while the carbon is useful for an anodic electrode in the pyrochemical process.

\section{ACKNOWLEDGEMENTS}

This work was supported under the Mid- and Long-term Nuclear Research and Development Program through the National Research Foundation of Korea (NRF-2014000288) funded by the Korean Ministry of Science, ICT and Future Planning.

\section{REFERENCES}

1. J.H. Yoo, B.J. Lee, H.S. Lee and E.H. Kim, J. Kor. Radioact. Waste Soc., 5, 283 (2007).

2. J.H. Yoo, C.S. Seo, E.H. Kim and H.S. Lee, Nucl. Eng. Technol., 40, 581 (2008).

3. T. Nagai, A. Uehara, T. Fujii, O. Shirai, N. Sato and H. Yamana, J. Nucl. Sci. Technol., 42, 1025 (2005).

4. D.H. Kim, S.E. Bae, J.Y. Kim, T.H. Park, Y.J. Park and K. Song, Asian J. Chem., 25, 7055 (2013).

5. J.Y. Kim, Y.S. Choi, S.E. Bae, I. Yum, D.H. Kim, J.W. Yeon and K. Song, Asian J. Chem., 25, 7028 (2013).

6. J.H. Lee, Y.H. Kang, S.C. Hwang, I.B. Shim, E.H. Kim and S.W. Park, Nucl. Technol., 162, 135 (2008).

7. Y.H. Kang, J.H. Lee, S.C. Hwang, J.B. Shim, E.H. Kim and S.W. Park, Carbon, 44, 3142 (2006).

8. J.C. Gabriel, D. Vincent, J. Bouteillon, J.C. Poignet, V.A. Volkovich and T.R. Griffiths, Electrochim. Acta, 44, 4619 (1999).

9. S.-E. Bae, Y.J. Park, S.K. Min, Y.H. Cho and K. Song, Electrochim. Acta, 55, 3022 (2010).

10. S.-E. Bae, Y.-H. Cho, Y.J. Park, H.J. Ahn and K. Song, Electrochem. Solid-State Lett., 13, F25 (2010).

11. M. Gibilaro, L. Massot, P. Chamelot and P. Taxil, J. Nucl. Mater., 382, 39 (2008).

12. P. Allongue, C. Henry de Villeneuve, S. Morin, R. Boukherroub and D.D.M. Wayner, Electrochim. Acta, 45, 4591 (2000). 